\title{
E-Shaped Linear Array Antenna for Ku Band on Alumina Substrate
}

\author{
Medhavi Agarwal \\ (Microelectronics Engg, I.E.T., G.B.T.U. ,Lucknow, India)
}

\begin{abstract}
An E-Shaped Linear Array Antenna design for Ku band is presented here on Alumina Substrate. The substrate made with Aluminum Oxide $\left(\mathrm{Al}_{2} \mathrm{O}_{3}\right)$ has high dielectric constant (9.8) and is $1.5 \mathrm{~mm}$ thick. The patch's dimension is $3.5 \mathrm{~mm} \times 5.0 \mathrm{~mm}$ for miniaturized antenna and the slots of unequal width $2.8 \mathrm{~mm} x 1.5 \mathrm{~m}$ and $3 m m \times 2 m m$ are introduced here for gain maximization. The finite element method is used to design and analyse the presented antenna array. The impedance bandwidth for this array antenna comes out to be approximately $2.8 \mathrm{GHz}$ (46.67\% of entire Ku band). This proposed antenna is able to give a gain of $4.48 \mathrm{~dB}$ for the Ku band frequency range and almost a stable radiation pattern throughout the $12 \sim 18 \mathrm{GHz}$ frequency range. The projected antenna array is designed and simulated by using Ansoft's 3D full-wave electromagnetic field software HFSS.
\end{abstract}

Keywords : $\mathrm{Al}_{2} \mathrm{O}_{3}$,Array,Dielectric, Gain, Return Loss,

\section{Introduction}

The Antenna technology for satellite applications is an interesting commercial market for the mobile satellite terminals. Ku band is very popular for different satellite communication services, because of small component size and less interference at higher frequencies. The effective size of the antenna element is less resulting in miniaturised antenna array which is very useful for satellite communication. It has been found that the $\mathrm{Al}_{2} \mathrm{O}_{3}$ ceramic material substrate has low loss at higher communication frequencies and has high dielectric constant hence is suitable for antenna miniaturisation for Ku band frequencies. However in order to reduce antenna size, geometry and material properties are to be chosen carefully. Microstrip patch antennas are commonly used for antenna miniaturization because of their advantages of low-cost, lightweight and these antennas can be easily integrated into mobile systems as a part of the circuit board containing other sub-systems.

\section{ARRAY ELEMENT DESIGN}

The first step to simulate a structure using HFSS is to define the geometry of the structure by giving the material properties and boundaries for 3D or 2D elements available in HFSS and then to draw the intended architecture using the drawing tools available in the software. The designed structure is excited using the suitable port excitation schemes. The next step is the assigning of boundary scheme. Now, the simulation engine can be invoked by giving the proper frequency of operation and the number of frequency points. Finally the simulation results can be displayed.

The first step is the design of element's radiating E-shaped patch which can be obtained by cutting slots from a rectangular shaped copper patch on substrate with small ground plane. A coaxial probe feed antenna geometry is then to be designed on the $\mathrm{Al}_{2} \mathrm{O}_{3}$ ceramic material substrate[1]. The patch is fed by conventional coaxial probe with $0.2 \mathrm{~mm}$ radius and $1.5 \mathrm{~mm}$ height intersecting the substrate.

The dimension of the radiating patch is determined from the mathematical equations:

$\mathrm{W}=\left(\mathrm{c} / 2 \mathrm{f}_{0}\right) \sqrt{ }\left(\varepsilon_{\mathrm{r}}+1\right) / 2$

$\mathrm{L}=\left(\mathrm{c} / 2 \mathrm{f}_{0} \sqrt{ } \varepsilon_{\mathrm{r}}\right) * 2 \Delta \mathrm{l}$

Where $\mathrm{W}$ is the width and $\mathrm{L}$ is the length of the patch, $f \mathrm{o}$ is the centre target frequency, $\mathrm{c}$ is the speed of light in vacuum[3].

The effective dielectric constant, $\varepsilon_{\text {reff }}$ and Frings Factor $\Delta \mathrm{L}$ can be determined as:

$\varepsilon_{\text {reff }}=\left(\varepsilon_{\mathrm{r}}+1\right) / 2+\left(\varepsilon_{\mathrm{r}}-1\right) / 2(1+\mathrm{h} / \mathrm{W})^{-1 / 2}$

Frings factor $\Delta \mathrm{L}=0.412 \mathrm{~h}\left\{\left(\varepsilon_{\text {reff }}+0.3\right)(\mathrm{W} / \mathrm{h}+0.264) /\left(\varepsilon_{\text {reff }}-0.258\right)(\mathrm{W} / \mathrm{h}+0.8)\right\}$

Then the effective length would be:

Effective Length $\mathrm{L}_{\text {eff }}=\mathrm{c} /\left(2 \mathrm{f}_{0} \sqrt{ } \varepsilon_{\text {reff }}\right)$

Length $\mathrm{L}=\mathrm{L}_{\text {eff- } 2} \Delta \mathrm{L}$

The 3D view of proposed array element is shown in Fig.1. 


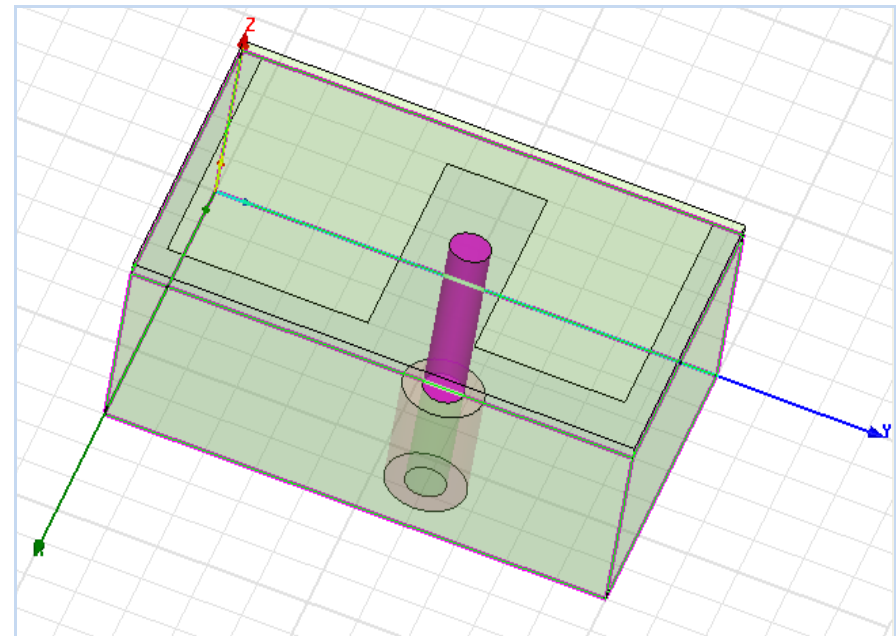

Fig.1: 3D View of Proposed Antenna Element

Fig.2, 3 and 4 show the result of the return loss, VSWR and Gain of the proposed patch antenna element.

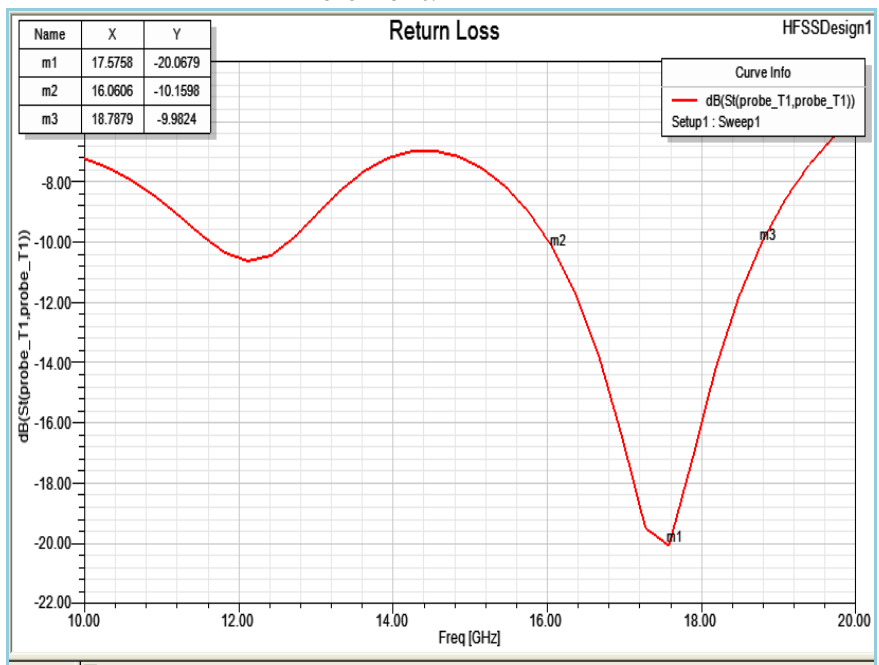

Fig.2: Return Loss of Proposed Antenna Element

The return loss achieved is less than the $-10 \mathrm{~dB}$ accurately it is $-20.06 \mathrm{~dB}$. The simulated bandwidth of $2.8 \mathrm{GHz}, 46.67 \%$ of entire $\mathrm{Ku}-\mathrm{Band}(12 \mathrm{GHz} \sim 18 \mathrm{GHz})$ is achieved. The VSWR value comes out to be less than 2 , i.e. 1.22 which can be considered suitable for the antenna but the maximum gain $-1.54 \mathrm{~dB}$ is obtained from the single element design and the resonance frequency is $17.57 \mathrm{GHz}$.

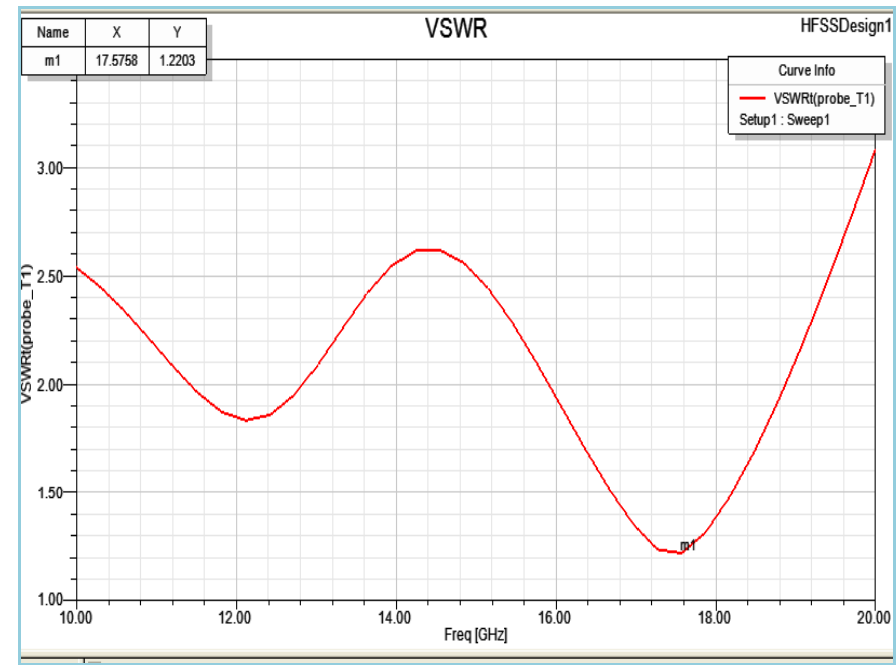

Fig.3: VSWR of Proposed Antenna Element 


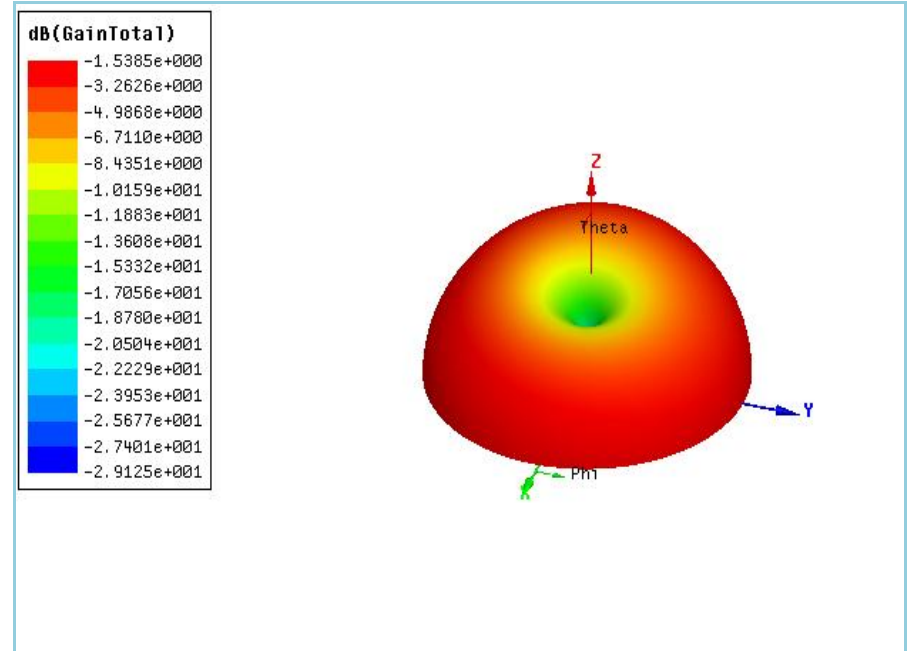

Fig.4: Gain of Proposed Antenna Element

From the above analysis we see that the gain variation across the operating band does not come out to be satisfactory. Hence now we would design an antenna array for better performance and desired results.

\section{DESIGN AND ANALYSIS OF VARIOUS ARRAYS}

Here first we propose $2 \mathrm{x} 1$ antenna array geometry. The first cell is placed at $\mathrm{X}, \mathrm{Y}, \mathrm{Z}$ as 0,0 , and 0 . All the dimensions are taken to be in $\mathrm{mm}$. The $\mathrm{U}$ vector direction is $\mathrm{X}, \mathrm{Y}, \mathrm{Z}$ as $1,0,0$ and the $\mathrm{V}$ vector direction is $\mathrm{X}, \mathrm{Y}, \mathrm{Z}$ as $0,1,0$.

Then we have to choose the distance between the cells i.e. the distance between the array elements. This distance should be less than the half wavelength of the antenna for the highest frequency. So we have chosen the distance between the antenna array elements to be only $1 \mathrm{~mm}$. The number of elements is 2 for $\mathrm{U}$ vector direction. This constitutes a single dimensional array antenna[4].

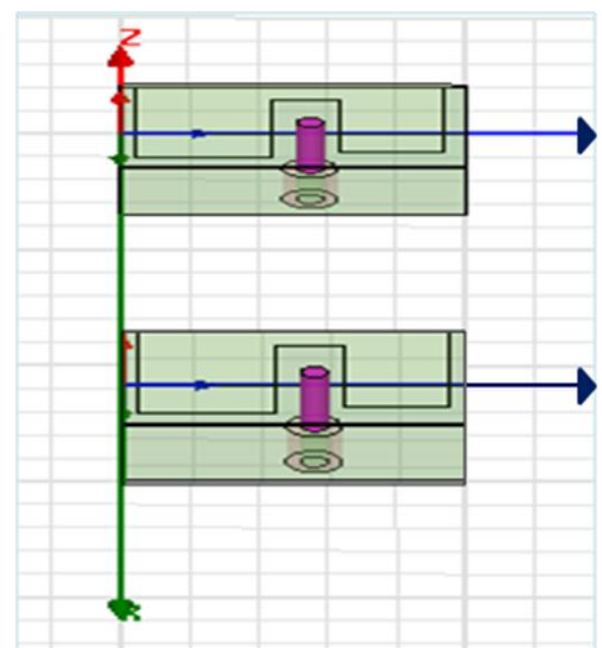

Fig.5: 3D View of Antenna 2x1 Array

This antenna array can give a bandwidth of around $2.8 \mathrm{GHz}$ for Ku-band of operation from $12 \mathrm{GHz}$ to $18 \mathrm{GHz}$ with a return loss lower than $-10 \mathrm{~dB}$. VSWR value comes out to be 1.22 for resonant frequency 17.58 GHz. The achieved gain is $4.48 \mathrm{~dB}$.We see that the Return Loss and VSWR comes almost same as that of single element antenna i.e. $-20.6 \mathrm{~dB}$ and 1.22 , but the gain comes out to be $1.47 \mathrm{~dB}$ from the designed $2 \mathrm{x} 1$ antenna array and the resonance frequency is $17.58 \mathrm{GHz}$. 


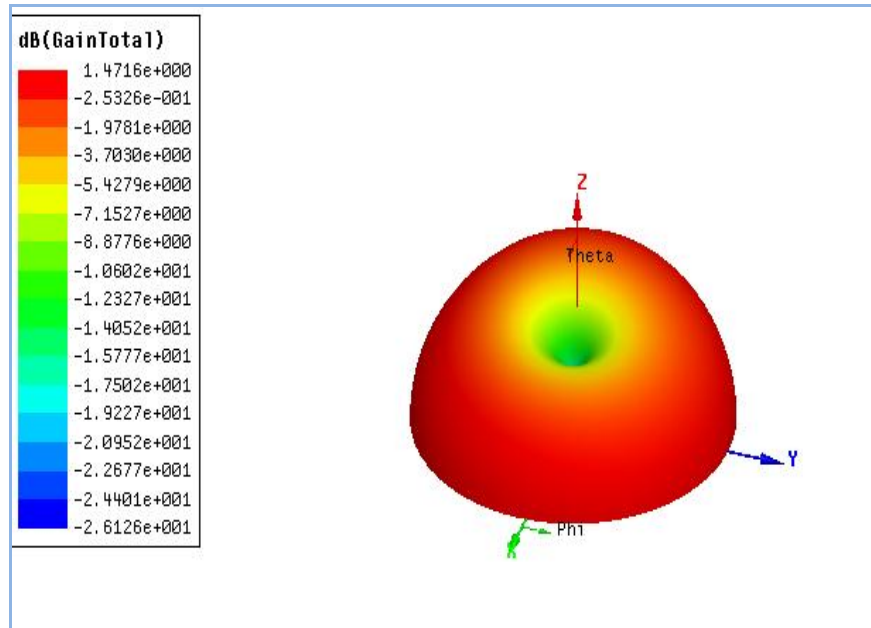

Fig.6: Gain of Antenna 2x1 Array
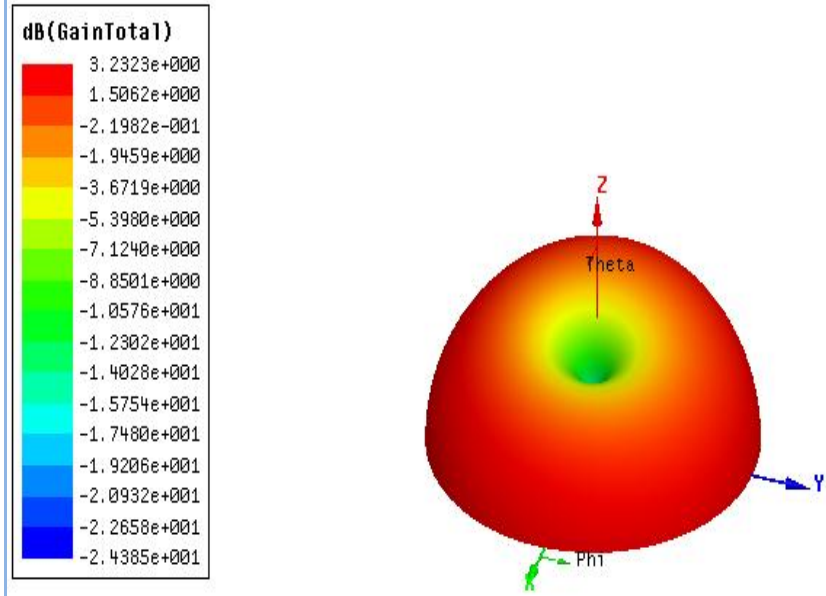

Fig.7: Gain of Antenna 3x1 Array

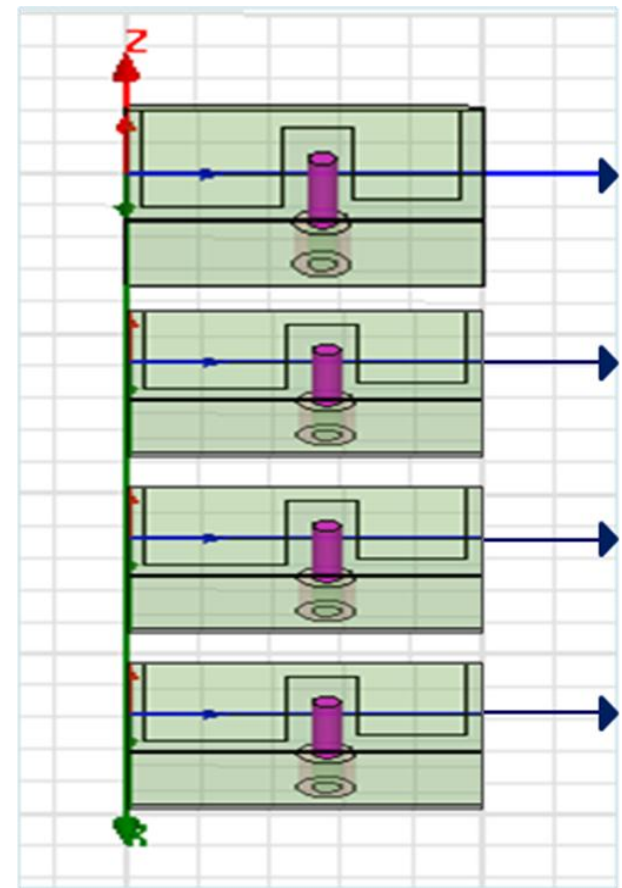

Fig.8: 3D View of Antenna 4x1 Array 
Similarly we design $3 \times 1$ array and find that the gain comes out to be $3.23 \mathrm{~dB}$ from the designed $3 \times 1$ antenna array and the resonance frequency is still $17.58 \mathrm{GHz}$. For $2 \times 2$ array gain comes out to be nearly 4.36 $\mathrm{dB}$ and for the $4 \times 1$ array the maximum gain $4.48 \mathrm{~dB}$ can be obtained at resonance frequency $17.58 \mathrm{GHz}$.

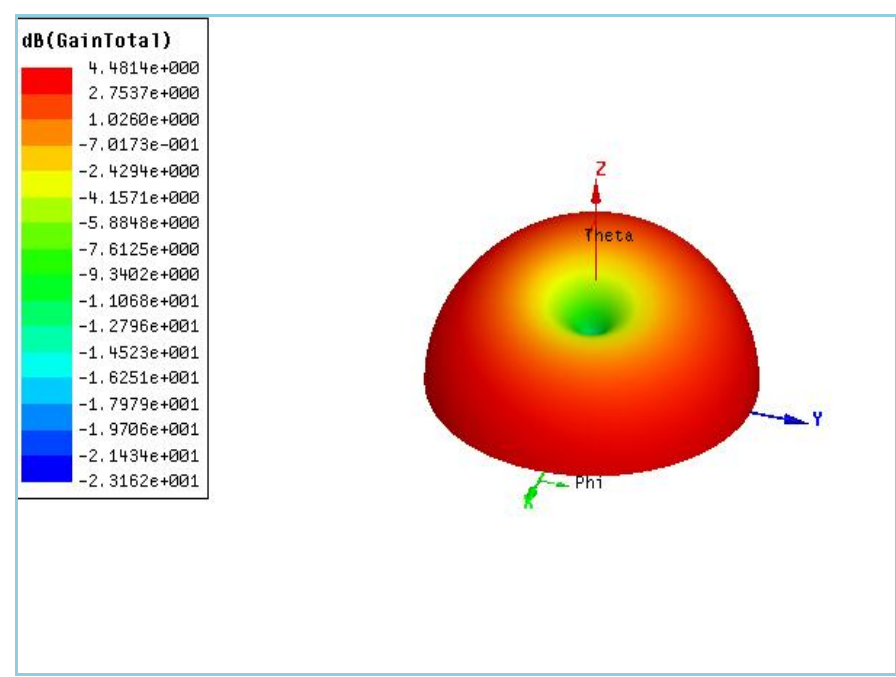

Fig.9: Gain of Antenna 4x1 Array

IV.

CONCLUSION

By looking at the all parameters we can study our design by a comparative analysis. So a comparative analysis for the different microstrip patch antenna arrays is compiled here in the following table:

Table: Comparative analysis of antenna arrays

\begin{tabular}{|c|c|c|c|c|c|}
\hline ANTENNA & $\mathbf{1}$ E. & $\mathbf{2 x 1}$ & $\mathbf{3 x 1}$ & $\mathbf{2 x 2}$ & $\mathbf{4 x 1}$ \\
\hline Return Loss(dB) & -20.6 & -20.6 & -20.6 & -20.6 & -20.6 \\
\hline B.W.(GHz) & 2.8 & 2.8 & 2.8 & 2.8 & 2.8 \\
\hline VSWR & 1.22 & 1.22 & 1.22 & 1.22 & 1.22 \\
\hline Gain(dB) & -1.54 & 1.47 & 3.23 & 4.36 & 4.48 \\
\hline Q Factor & 5.36 & 5.36 & 5.36 & 5.36 & 5.36 \\
\hline Directivity & 0.70 & 1.41 & 2.11 & 2.74 & 2.82 \\
\hline Res. Freq. $(\mathbf{G H z})$ & 17.58 & 17.58 & 17.58 & 17.58 & 17.58 \\
\hline
\end{tabular}

We see that although the size of proposed antenna is increased for the array, but the gain remains higher compared to that of the corresponding single element antennas. Similarly the Directivity for single element array comes out to be 0.705 whereas the Directivity of 2.82 is achieved for $4 \times 1$ microstrip patch antenna array. Hence, $4 \times 1$ array comes out to be as a good solution at the desired frequency range.

An E-shaped electrically small coaxial probe fed microstrip patch antenna array on $\mathrm{Al}_{2} \mathrm{O}_{3}$ ceramic material substrate with 9.8 dielectric constant can be designed with very small dimensions for the operation in $\mathrm{Ku}$ band. The designed antenna can be easily fabricated and placed on the small devices or can be integrated into mobile systems as a part of the circuit board containing other sub-systems. This antenna is very useful for applications in satellite communications and wireless applications.

\section{REFERENCES}

[1] M. Habibullah and M. T. Islam ,J.S. Mandeep, N. Misran, Design and Analysis of A Multi Band Electrically Small Antenna Using Ceramic Material Substrate. PRZEGLACD ELEKTROTECHNICZNY, ISSN pp. 0033-2097, R. 89 NR.

[2] Shatabdi Chakraborty, Shweta Srivastava, Nov-Dec. 2012 .Ku Band Annular Ring Antenna on Different PBG Substrates, International Journal of Modern Engineering Research (IJMER), Vol.2, Issue.6, pp-4726-4731.

[3] M.Habibullah and M. T Islam., 2012. Design of a modified W shaped patch antenna on ceramic material substrate for Ku band, Chalcogenide Letters, vol. 9, no. 2, pp. 61-66.

[4] Wong Kin-Lu, 2002. Compact and Broadband Microstrip Antennas, A WILEY-Interscience publication.

[5] Balanis C. A., 1982, Antenna Theory: Analysis and Design, Second Edition, John Wiley \& Sons Inc.

[6] Bahl, I.J. and Bhartia P., 1980. Microstrip Antennas. 2nd Edn., Artech House, Boston, London.

[7] Anubhuti Khare, Rajesh Nema, Puran Gour, November 2010. New Multiband E-Shape Microstrip Patch Antenna on RT DUROID 5880 Substrate and RO4003 Substrate for Pervasive Wireless Communication, International Journal of Computer Applications, Vol.9-No.8, pp. 0975 - 8887. 